\title{
ANTI-SYNCHRONIZATION OF 4-DIMENSIONAL HYPERCHAOTIC LI AND HYPERCHAOTIC LÜ SYSTEMS VIA ACTIVE CONTROL
}

\author{
Sundarapandian Vaidyanathan ${ }^{1}$ \\ ${ }^{1}$ Research and Development Centre, Vel Tech Dr. RR \& Dr. SR Technical University \\ Avadi, Chennai-600 062, Tamil Nadu, INDIA \\ sundarvtu@gmail.com
}

\begin{abstract}
In this paper, we derive new results for the anti-synchronization of identical and non-identical hyperchaotic Li systems (Li, Tang and Chen, 2005) and hyperchaotic Lü systems (Bao and Liu, 2008). Active control method has been deployed for achieving the four-dimensional hyperchaotic systems discussed in this paper and the stability results have been proved using Lyapunov stability theory. Since the Lyapunov exponents are not required for these calculations, the active nonlinear control method is effective and convenient to achieve anti-synchronization of the identical and different hyperchaotic Li systems and hyperchaotic Lü systems. Numerical simulations using MATLAB have been shown to illustrate the antisynchronization controllers designed in this paper.
\end{abstract}

\section{KEYWORDS}

Anti-Synchronization, Active Control, Chaos, Hyperchaotic Li System, Hyperchaotic Lü System.

\section{INTRODUCTION}

Hyperchaotic system is typically defined as a chaotic system having more than one positive Lyapunov exponent (LE). It was first discovered by O.E. Rössler ([1], 1979).

Hyperchaotic systems have the characteristics of high capacity, high security and high efficiency. Hence, they find applications in several areas like electronic oscillators [2-3], secure communication [4-7], synchronization [8-9], encryption [10], etc. Thus, control and synchronization of hyperchaotic systems have become important research problems.

The anti-synchronization problem can be stated as follows. If a particular chaotic system is called the master system and another chaotic system is called the slave system, then the idea of antisynchronization is to use the output of the master system to control the slave system so that the states of the slave system have the same amplitude but opposite signs as the states of the master system asymptotically with time.

Since the seminal work by Pecora and Carroll ([11], 1990), many impressive methods have been developed for the synchronization and anti-synchronization of chaotic systems, viz. OGY method [12], active control method [13-15], adaptive control method [16-20], backstepping method [2124], sampled-data feedback synchronization method [25-26], time-delay feedback method [2728], sliding mode control method [29-32], etc.

DOI : $10.5121 /$ ijctcm.2012.2603 
In this paper, we deploy active control method to derive new results for the anti-synchronization for identical and different hyperchaotic Li systems ([33], 2005) and hyperchaotic Lü systems ([34], 2008).

The organization of this paper is as follows. Section 2 contains the problem statement and active control methodology, Section 3 provides a description of the hyperchaotic Li and hyperchaotic Lü systems. Section 4 contains our new results for the anti-synchronization of two identical hyperchaotic Li systems. Section 5 contains our new results for the anti-synchronization of two identical hyperchaotic Lü systems. Section 6 contains our new results for the anti-synchronization of hyperchaotic Li and hyperchaotic Lü systems. Section 7 contains a summary of the main results derived in this paper.

\section{Problem Statement and ACtive control Methodology}

As the master system, we consider the chaotic system described by the dynamics

$$
\dot{x}=A x+f(x)
$$

where $x \in R^{n}$ is the state of the system, $A$ is the $n \times n$ matrix of the system parameters and $f: R^{n} \rightarrow R^{n}$ is the nonlinear part of the system.

As the slave system, we consider the chaotic system described by the dynamics

$$
\dot{y}=B y+g(y)+u
$$

where $y \in R^{n}$ is the state of the system, $B$ is the $n \times n$ matrix of the system parameters, $g: R^{n} \rightarrow R^{n}$ is the nonlinear part of the system and $u \in R^{n}$ is the active controller of the slave system.

If $A=B$ and $f=g$, then $x$ and $y$ are the states of two identical chaotic systems. If $A \neq B$ or $f \neq g$, then $x$ and $y$ are the states of two different chaotic systems.

For the master system (1) and the slave system (2), the design goal is to build a feedback controller $u$, which anti-synchronizes their states for all initial conditions $x(0), y(0) \in R^{n}$.

We define the anti-synchronization error as

$$
e=y+x
$$

Then a simple calculation yields the error dynamics as

$$
\dot{e}=B y+A x+g(y)+f(x)+u
$$

In the anti-synchronization problem, we wish to find a feedback controller $u$ so that

$$
\lim _{t \rightarrow \infty}\|e(t)\|=0 \text { for all } e(0) \in R^{n}
$$

We take as a candidate Lyapunov function 
International Journal of Control Theory and Computer Modelling (IJCTCM) Vol.2, No.6, November 2012

$$
V(e)=e^{T} P e,
$$

where $P$ is a positive definite matrix.

Note that $V: R^{n} \rightarrow R$ is a positive definite function by construction. We assume that the parameters of the master and slave system are known and that the states of both systems (1) and (2) are measurable.

If we find a feedback controller $u$ so that

$$
\dot{V}(e)=-e^{T} Q e,
$$

where $Q$ is a positive definite matrix, then $\dot{V}: R^{n} \rightarrow R$ is a negative definite function.

Thus, by Lyapunov stability theory [35], the error dynamics (4) is globally exponentially stable. Hence, it follows that the states of the master system (1) and the slave system (2) will be globally and exponentially anti-synchronized.

\section{SYSTEMS DESCRIPTION}

The hyperchaotic Li system ([33], 2005) is described by the 4-D dynamics

$$
\begin{aligned}
& \dot{x}_{1}=a\left(x_{2}-x_{1}\right)+x_{4} \\
& \dot{x}_{2}=d x_{1}-x_{1} x_{3}+c x_{2} \\
& \dot{x}_{3}=-b x_{3}+x_{1} x_{2} \\
& \dot{x}_{4}=x_{2} x_{3}+\eta x_{4}
\end{aligned}
$$

where $x_{1}, x_{2}, x_{3}, x_{4}$ are the states and $a, b, c, d, \eta$ are constant, positive parameters of the system. The 4-D system (8) exhibits a hyperchaotic attractor, when the parameter values are taken as

$$
a=35, \quad b=3, c=12, d=7, \quad \eta=0.6
$$

The phase portrait of the hyperchaotic Li system is shown in Figure 1.

The hyperchaotic Lü system ([34], 2008) is described by the 4-D dynamics

$$
\begin{aligned}
& \dot{x}_{1}=\alpha\left(x_{2}-x_{1}\right)+x_{4} \\
& \dot{x}_{2}=\gamma x_{2}-x_{1} x_{3} \\
& \dot{x}_{3}=-\beta x_{3}+x_{1} x_{2} \\
& \dot{x}_{4}=\varepsilon x_{1}+\delta x_{2} x_{3}
\end{aligned}
$$

where $x_{1}, x_{2}, x_{3}, x_{4}$ are the states and $\alpha, \beta, \gamma, \delta, \varepsilon$ are constant, positive parameters of the system.

The 4-D system (10) exhibits a hyperchaotic attractor, when the parameter values are taken as

$$
\alpha=36, \quad \beta=3, \quad \gamma=20, \quad \delta=0.1, \quad \varepsilon=21
$$


International Journal of Control Theory and Computer Modelling (IJCTCM) Vol.2, No.6, November 2012

The phase portrait of the hyperchaotic Lü system is shown in Figure 2.
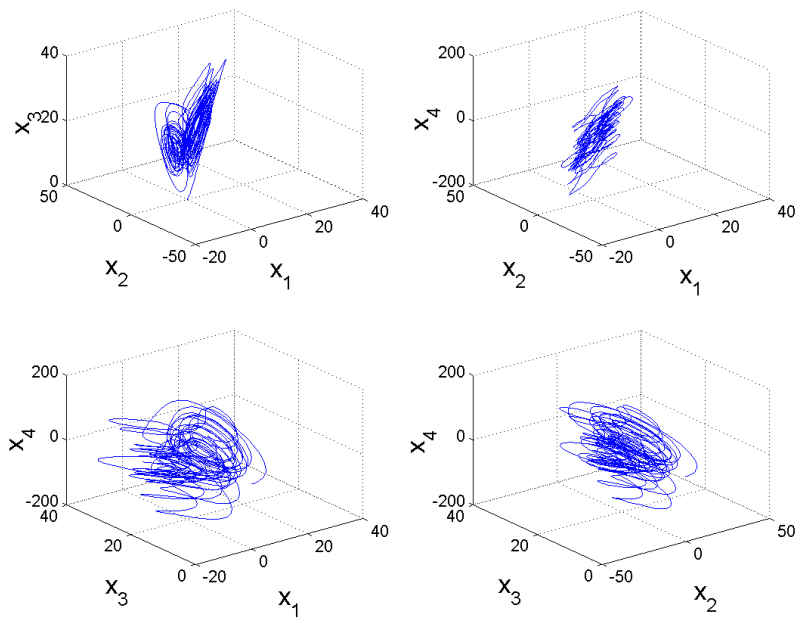

Figure 1. The Phase Portrait of the Hyperchaotic Li System
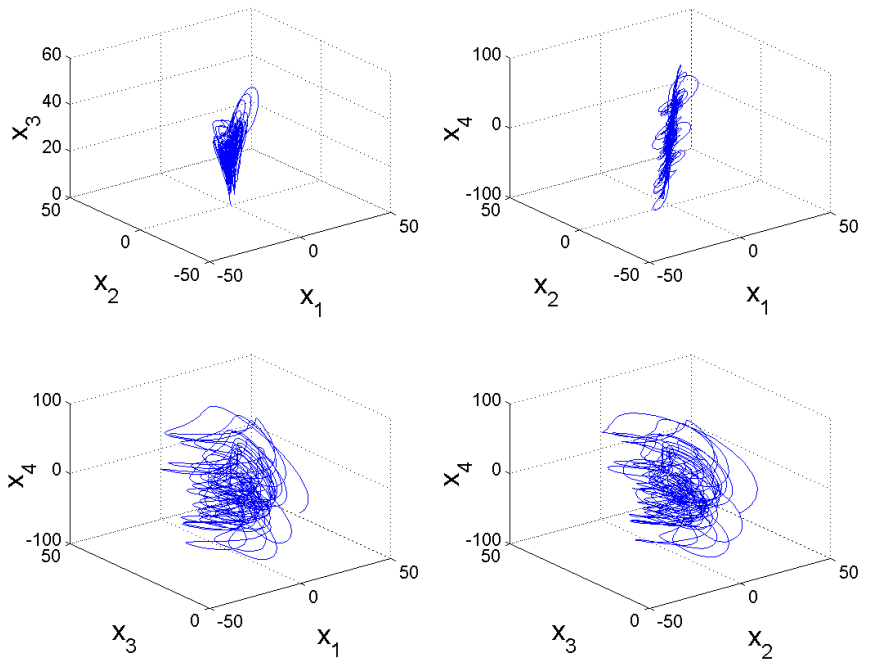

Figure 2. The Phase Portrait of the Hyperchaotic Lü System

\section{Anti-Synchronization of Identical Hyperchaotic Li Systems ViA ACTIVe Control}

\subsection{Theoretical Results}

In this section, we derive new results for the anti-synchronization of two identical hyperchaotic $\mathrm{Li}$ systems (2005) via active control.

As the master system, we take the hyperchaotic Li dynamics 
International Journal of Control Theory and Computer Modelling (IJCTCM) Vol.2, No.6, November 2012

$$
\begin{aligned}
& \dot{x}_{1}=a\left(x_{2}-x_{1}\right)+x_{4} \\
& \dot{x}_{2}=d x_{1}-x_{1} x_{3}+c x_{2} \\
& \dot{x}_{3}=-b x_{3}+x_{1} x_{2} \\
& \dot{x}_{4}=x_{2} x_{3}+\eta x_{4}
\end{aligned}
$$

where $x_{1}, x_{2}, x_{3}, x_{4}$ are the states and $a, b, c, d, \eta$ are positive parameters of the system.

As the slave system, we take the controlled hyperchaotic Li dynamics

$$
\begin{aligned}
& \dot{y}_{1}=a\left(y_{2}-y_{1}\right)+y_{4}+u_{1} \\
& \dot{y}_{2}=d y_{1}-y_{1} y_{3}+c y_{2}+u_{2} \\
& \dot{y}_{3}=-b y_{3}+y_{1} y_{2}+u_{3} \\
& \dot{y}_{4}=y_{2} y_{3}+\eta y_{4}+u_{4}
\end{aligned}
$$

where $y_{1}, y_{2}, y_{3}, y_{4}$ are the states and $u_{1}, u_{2}, u_{3}, u_{4}$ are the active nonlinear controls.

The anti-synchronization error $e$ is defined by

$$
e_{i}=y_{i}+x_{i}, \quad(i=1,2,3,4)
$$

The error dynamics is obtained as

$$
\begin{aligned}
& \dot{e}_{1}=a\left(e_{2}-e_{1}\right)+e_{4}+u_{1} \\
& \dot{e}_{2}=d e_{1}+c e_{2}-y_{1} y_{3}-x_{1} x_{3}+u_{2} \\
& \dot{e}_{3}=-b e_{3}+y_{1} y_{2}+x_{1} x_{2}+u_{3} \\
& \dot{e}_{4}=\eta e_{4}+y_{2} y_{3}+x_{2} x_{3}+u_{4}
\end{aligned}
$$

We choose the active nonlinear controller as

$$
\begin{aligned}
& u_{1}=-a\left(e_{2}-e_{1}\right)-e_{4}-k_{1} e_{1} \\
& u_{2}=-d e_{1}-c e_{2}+y_{1} y_{3}+x_{1} x_{3}-k_{2} e_{2} \\
& u_{3}=b e_{3}-y_{1} y_{2}-x_{1} x_{2}-k_{3} e_{3} \\
& u_{4}=-\eta e_{4}-y_{2} y_{3}-x_{2} x_{3}-k_{4} e_{4}
\end{aligned}
$$

where the gains $k_{i},(i=1,2,3,4)$ are positive constants.

Substituting (16) into (15), the error dynamics simplifies to

$$
\dot{e}_{i}=-k_{i} e_{i}, \quad(i=1,2,3,4)
$$

Next, we prove the following result. 
Theorem 4.1. The active nonlinear controller defined by (16) achieves the global and exponential anti-synchronization of the identical hyperchaotic Li systems (12) and (13).

Proof. Consider the quadratic Lyapunov function defined by

$$
V(e)=\frac{1}{2} e^{T} e=\frac{1}{2}\left(e_{1}^{2}+e_{2}^{2}+e_{3}^{2}+e_{4}^{2}\right),
$$

which is a positive definite function on $R^{4}$.

Differentiating (18) along the trajectories of (17), we get

$$
\dot{V}(e)=-k_{1} e_{1}^{2}-k_{2} e_{2}^{2}-k_{3} e_{3}^{2}-k_{4} e_{4}^{2}
$$

which is a negative definite function on $R^{4}$.

Hence, by Lyapunov stability theory [35], the error dynamics (17) is globally exponentially stable. This completes the proof.

\subsection{Numerical Results}

For MATLAB simulations, the fourth-order Runge-Kutta method with time-step $h=10^{-8}$ is used to solve the differential equations (12) and (13) with the active nonlinear controller (16).

The feedback gains used in the equation (16) are chosen as

$$
k_{1}=5, k_{2}=5, k_{3}=5, k_{4}=5
$$

The parameters of the hyperchaotic Li systems are chosen as

$$
a=35, \quad b=3, \quad c=12, d=7, \quad \eta=0.6
$$

The initial conditions of the master system (12) are chosen as

$$
x_{1}(0)=18, \quad x_{2}(0)=6, \quad x_{3}(0)=-10, \quad x_{4}(0)=-25
$$

The initial conditions of the slave system (13) are chosen as

$$
y_{1}(0)=25, \quad y_{2}(0)=-15, \quad y_{3}(0)=22, \quad y_{4}(0)=-12
$$

Figure 3 shows the anti-synchronization of the identical hyperchaotic Li systems.

Figure 4 shows the time-history of the anti-synchronization errors $e_{1}, e_{2}, e_{3}, e_{4}$. 

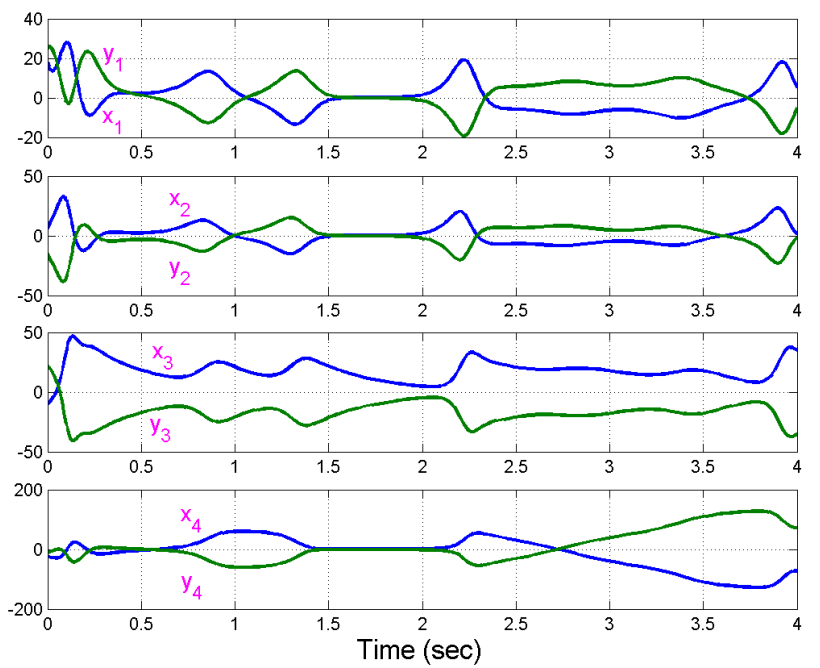

Figure 3. Anti-Synchronization of the Identical Hyperchaotic Li Systems

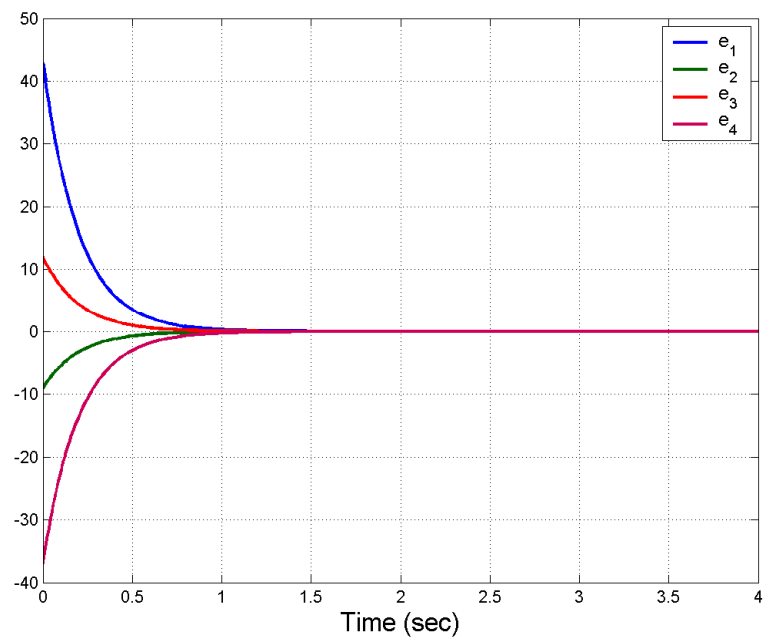

Figure 4. Time-History of the Anti-Synchronization Error

\section{Anti- Synchronization of Identical Hyperchaotic Lü SyStems BY ACTIVE CONTROL}

\subsection{Theoretical Results}

In this section, we derive new results for the anti-synchronization of two identical hyperchaotic Lü systems (2008) via active control.

As the master system, we take the hyperchaotic Lü dynamics 
International Journal of Control Theory and Computer Modelling (IJCTCM) Vol.2, No.6, November 2012

$$
\begin{aligned}
& \dot{x}_{1}=\alpha\left(x_{2}-x_{1}\right)+x_{4} \\
& \dot{x}_{2}=\gamma x_{2}-x_{1} x_{3} \\
& \dot{x}_{3}=-\beta x_{3}+x_{1} x_{2} \\
& \dot{x}_{4}=\varepsilon x_{1}+\delta x_{2} x_{3}
\end{aligned}
$$

where $x_{1}, x_{2}, x_{3}, x_{4}$ are the states and $\alpha, \beta, \gamma, \delta, \varepsilon$ are positive parameters of the system.

As the slave system, we take the controlled hyperchaotic Lü dynamics

$$
\begin{aligned}
& \dot{y}_{1}=\alpha\left(y_{2}-y_{1}\right)+y_{4}+u_{1} \\
& \dot{y}_{2}=\gamma y_{2}-y_{1} y_{3}+u_{2} \\
& \dot{y}_{3}=-\beta y_{3}+y_{1} y_{2}+u_{3} \\
& \dot{y}_{4}=\varepsilon y_{1}+\delta y_{2} y_{3}+u_{4}
\end{aligned}
$$

where $y_{1}, y_{2}, y_{3}, y_{4}$ are the states and $u_{1}, u_{2}, u_{3}, u_{4}$ are the active nonlinear controls.

The anti-synchronization error $e$ is defined by

$$
e_{i}=y_{i}+x_{i}, \quad(i=1,2,3,4)
$$

The error dynamics is obtained as

$$
\begin{aligned}
& \dot{e}_{1}=\alpha\left(e_{2}-e_{1}\right)+e_{4}+u_{1} \\
& \dot{e}_{2}=\gamma e_{2}-y_{1} y_{3}-x_{1} x_{3}+u_{2} \\
& \dot{e}_{3}=-\beta e_{3}+y_{1} y_{2}+x_{1} x_{2}+u_{3} \\
& \dot{e}_{4}=\varepsilon e_{1}+\delta\left(y_{2} y_{3}+x_{2} x_{3}\right)+u_{4}
\end{aligned}
$$

We choose the active nonlinear controller as

$$
\begin{aligned}
& u_{1}=-\alpha\left(e_{2}-e_{1}\right)-e_{4}-k_{1} e_{1} \\
& u_{2}=-\gamma e_{2}+y_{1} y_{3}+x_{1} x_{3}-k_{2} e_{2} \\
& u_{3}=\beta e_{3}-y_{1} y_{2}-x_{1} x_{2}-k_{3} e_{3} \\
& u_{4}=-\varepsilon e_{1}-\delta\left(y_{2} y_{3}+x_{2} x_{3}\right)-k_{4} e_{4}
\end{aligned}
$$

where the gains $k_{i},(i=1,2,3,4)$ are positive constants.

Substituting (24) into (23), the error dynamics simplifies to

$$
\dot{e}_{i}=-k_{i} e_{i}, \quad(i=1,2,3,4)
$$

Next, we prove the following result.

Theorem 5.1. The active nonlinear controller defined by (24) achieves the global and exponential anti-synchronization of the identical hyperchaotic Lü systems (20) and (21). 
International Journal of Control Theory and Computer Modelling (IJCTCM) Vol.2, No.6, November 2012

Proof. Consider the quadratic Lyapunov function defined by

$$
V(e)=\frac{1}{2} e^{T} e=\frac{1}{2}\left(e_{1}^{2}+e_{2}^{2}+e_{3}^{2}+e_{4}^{2}\right)
$$

which is a positive definite function on $R^{4}$.

Differentiating (26) along the trajectories of (25), we get

$$
\dot{V}(e)=-k_{1} e_{1}^{2}-k_{2} e_{2}^{2}-k_{3} e_{3}^{2}-k_{4} e_{4}^{2}
$$

which is a negative definite function on $R^{4}$.

Hence, by Lyapunov stability theory [35], the error dynamics (25) is globally exponentially stable. This completes the proof.

\subsection{Numerical Results}

For MATLAB simulations, the fourth-order Runge-Kutta method with time-step $h=10^{-8}$ is used to solve the differential equations (20) and (21) with the active nonlinear controller (24).

The feedback gains used in the equation (24) are chosen as

$$
k_{1}=5, k_{2}=5, k_{3}=5, k_{4}=5
$$

The parameters of the hyperchaotic Lü systems are chosen as

$$
\alpha=36, \quad \beta=3, \quad \gamma=20, \quad \delta=0.1, \quad \varepsilon=21
$$

The initial conditions of the master system (20) are chosen as

$$
x_{1}(0)=4, x_{2}(0)=26, x_{3}(0)=-20, \quad x_{4}(0)=15
$$

The initial conditions of the slave system (21) are chosen as

$$
y_{1}(0)=20, \quad y_{2}(0)=-17 \quad y_{3}(0)=-12, \quad y_{4}(0)=22
$$

Figure 5 shows the anti-synchronization of the identical hyperchaotic Lü systems.

Figure 6 shows the time-history of the anti-synchronization errors $e_{1}, e_{2}, e_{3}, e_{4}$. 

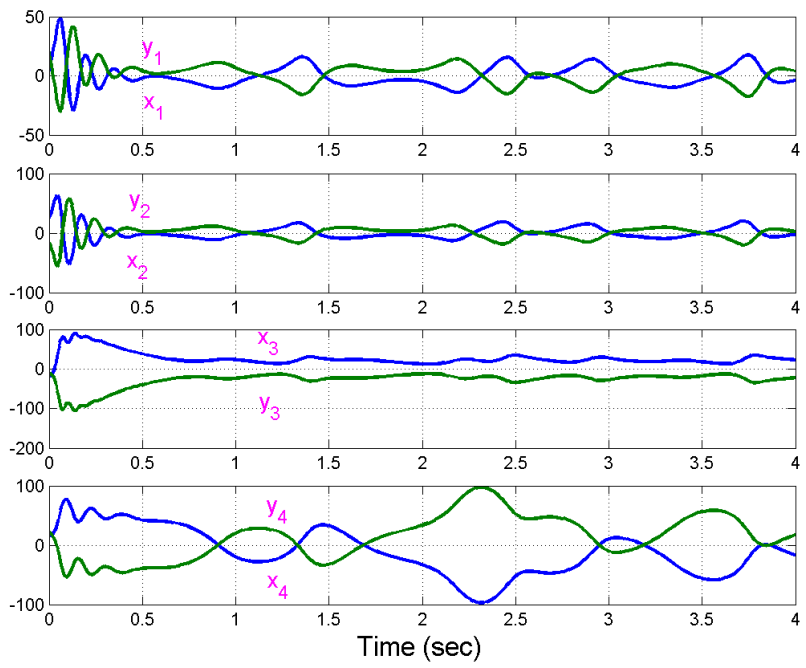

Figure 5. Anti-Synchronization of the Identical Hyperchaotic Lü Systems

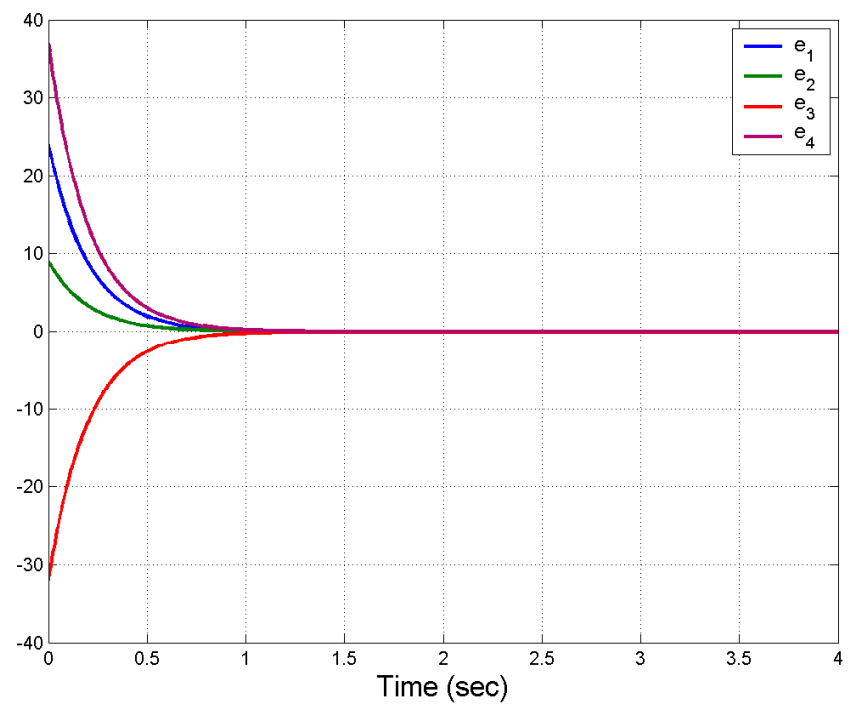

Figure 6. Time-History of the Anti-Synchronization Error

\section{ANTI- Synchronization of Non-IDENTICAl Hyperchaotic Li AND HYPERCHAOTIC LÜ SYSTEMS VIA ACTIVE CONTROL}

\subsection{Theoretical Results}

In this section, we apply the active nonlinear control method for the anti-synchronization of the non-identical hyperchaotic Li system (2005) and hyperchaotic Lü system (2008).

As the master system, we take the hyperchaotic Li dynamics 
International Journal of Control Theory and Computer Modelling (IJCTCM) Vol.2, No.6, November 2012

$$
\begin{aligned}
& \dot{x}_{1}=a\left(x_{2}-x_{1}\right)+x_{4} \\
& \dot{x}_{2}=d x_{1}-x_{1} x_{3}+c x_{2} \\
& \dot{x}_{3}=-b x_{3}+x_{1} x_{2} \\
& \dot{x}_{4}=x_{2} x_{3}+\eta x_{4}
\end{aligned}
$$

where $x_{1}, x_{2}, x_{3}, x_{4}$ are the states and $a, b, c, d, \eta$ are positive parameters of the system.

As the slave system, we take the controlled hyperchaotic Lü dynamics

$$
\begin{aligned}
& \dot{y}_{1}=\alpha\left(y_{2}-y_{1}\right)+y_{4}+u_{1} \\
& \dot{y}_{2}=\gamma y_{2}-y_{1} y_{3}+u_{2} \\
& \dot{y}_{3}=-\beta y_{3}+y_{1} y_{2}+u_{3} \\
& \dot{y}_{4}=\varepsilon y_{1}+\delta y_{2} y_{3}+u_{4}
\end{aligned}
$$

where $y_{1}, y_{2}, y_{3}, y_{4}$ are the states, $\alpha, \beta, \gamma, \delta, \mathcal{E}$ are positive parameters and $u_{1}, u_{2}, u_{3}, u_{4}$ are the active nonlinear controls. The anti-synchronization error $e$ is defined by

$$
e_{i}=y_{i}+x_{i}, \quad(i=1,2,3,4)
$$

The error dynamics is obtained as

$$
\begin{aligned}
& \dot{e}_{1}=\alpha\left(y_{2}-y_{1}\right)+a\left(x_{2}-x_{1}\right)+e_{4}+u_{1} \\
& \dot{e}_{2}=\gamma y_{2}+d x_{1}+c x_{2}-y_{1} y_{3}-x_{1} x_{3}+u_{2} \\
& \dot{e}_{3}=-\beta y_{3}-b x_{3}+y_{1} y_{2}+x_{1} x_{2}+u_{3} \\
& \dot{e}_{4}=\varepsilon y_{1}+\eta x_{4}+\delta y_{2} y_{3}+x_{2} x_{3}+u_{4}
\end{aligned}
$$

We choose the active nonlinear controller as

$$
\begin{aligned}
& u_{1}=-\alpha\left(y_{2}-y_{1}\right)-a\left(x_{2}-x_{1}\right)-e_{4}-k_{1} e_{1} \\
& u_{2}=-\gamma y_{2}-d x_{1}-c x_{2}+y_{1} y_{3}+x_{1} x_{3}-k_{2} e_{2} \\
& u_{3}=\beta y_{3}+b x_{3}-y_{1} y_{2}-x_{1} x_{2}-k_{3} e_{3} \\
& u_{4}=-\varepsilon y_{1}-\eta x_{4}-\delta y_{2} y_{3}-x_{2} x_{3}-k_{4} e_{4}
\end{aligned}
$$

where the gains $k_{i},(i=1,2,3,4)$ are positive constants.

Substituting (32) into (31), the error dynamics simplifies to

$$
\dot{e}_{i}=-k_{i} e_{i}, \quad(i=1,2,3,4)
$$

Next, we prove the following result.

Theorem 6.1. The active nonlinear controller defined by (32) achieves the global and exponential anti-synchronization of the hyperchaotic Li system (28) and hyperchaotic Lü system (29). 
International Journal of Control Theory and Computer Modelling (IJCTCM) Vol.2, No.6, November 2012

Proof. Consider the quadratic Lyapunov function defined by

$$
V(e)=\frac{1}{2} e^{T} e=\frac{1}{2}\left(e_{1}^{2}+e_{2}^{2}+e_{3}^{2}+e_{4}^{2}\right),
$$

which is a positive definite function on $R^{4}$.

Differentiating (34) along the trajectories of (44), we get

$$
\dot{V}(e)=-k_{1} e_{1}^{2}-k_{2} e_{2}^{2}-k_{3} e_{3}^{2}-k_{4} e_{4}^{2}
$$

which is a negative definite function on $R^{4}$.

Hence, by Lyapunov stability theory [35], the error dynamics (33) is globally exponentially stable. This completes the proof.

\subsection{Numerical Results}

For MATLAB simulations, the fourth-order Runge-Kutta method with time-step $h=10^{-8}$ is used to solve the differential equations (28) and (28) with the active nonlinear controller (24).

The feedback gains used in the equation (32) are chosen as $k_{i}=5,(i=1,2,3,4)$.

The parameters of the hyperchaotic Li and hyperchaotic Lü systems are chosen as

$$
a=35, b=3, c=12, d=7, \eta=0.6, \alpha=36, \beta=3, \gamma=20, \delta=0.1, \varepsilon=21
$$

The initial conditions of the master system (28) are chosen as

$$
x_{1}(0)=8, \quad x_{2}(0)=7, \quad x_{3}(0)=-10, x_{4}(0)=12
$$

The initial conditions of the slave system (29) are chosen as

$$
y_{1}(0)=32, \quad y_{2}(0)=-17, \quad y_{3}(0)=-22, \quad y_{4}(0)=4
$$

Figure 7 shows the anti-synchronization of the hyperchaotic Li and hyperchaotic Lü systems.

Figure 8 shows the time-history of the anti-synchronization errors $e_{1}, e_{2}, e_{3}, e_{4}$. 

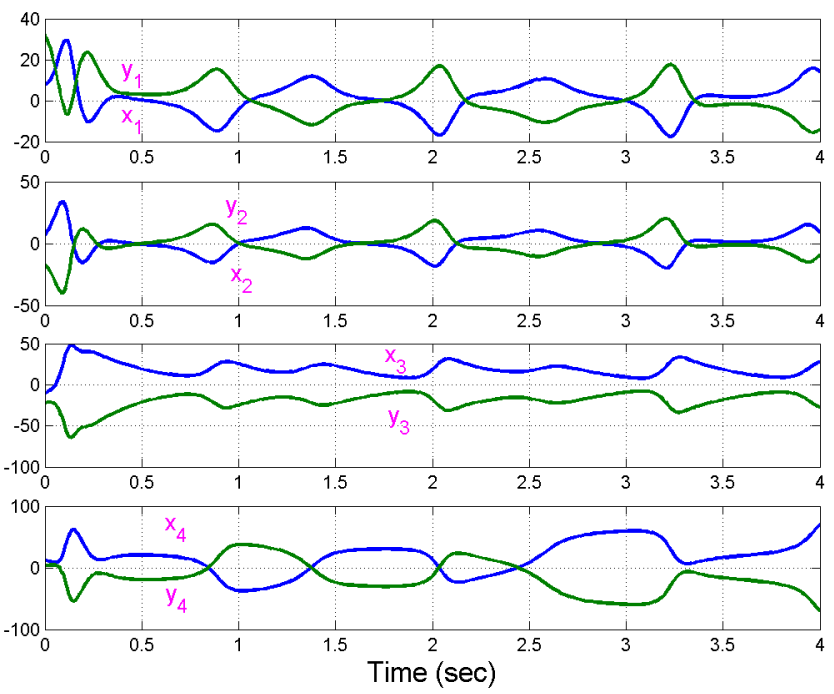

Figure 7. Anti-Synchronization of the Hyperchaotic Li and Hyperchaotic Lü Systems

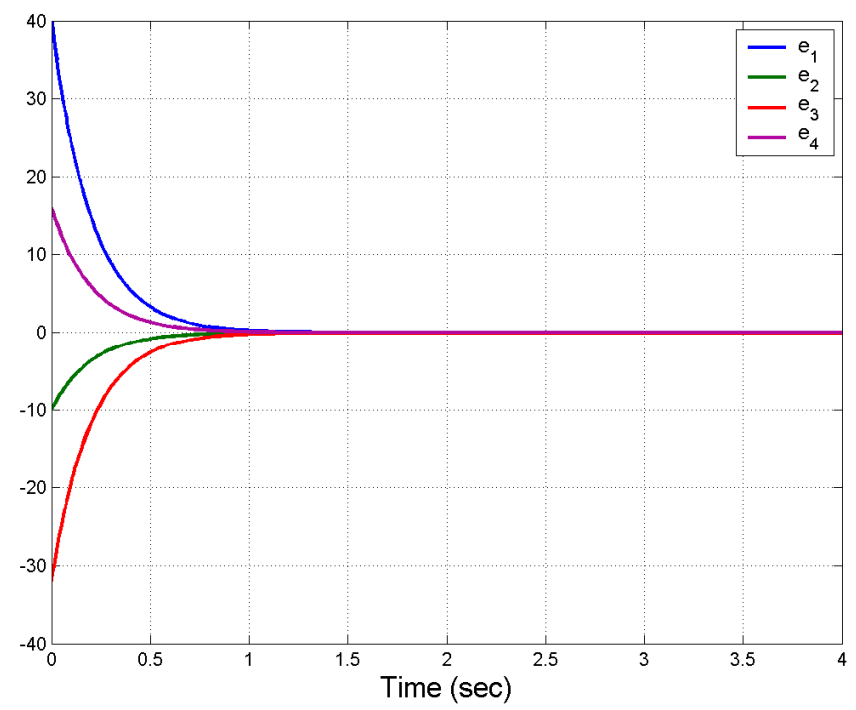

Figure 8. Time-History of the Anti-Synchronization Error

\section{Conclusions}

In this paper, active control method was applied to derive anti-synchronization results for the identical hyperchaotic Li systems (2005), identical hyperchaotic Lü systems (2008), and nonidentical hyperchaotic Li and hyperchaotic Lü systems. The stability results validating the antisynchronizing controllers have been proved using Lyapunov stability theory. Numerical simulations using MATLAB were presented to validate and demonstrate the efficiency of the anti-synchronization schemes derived for the hyperchaotic Li and hyperchaotic Lü systems. 
International Journal of Control Theory and Computer Modelling (IJCTCM) Vol.2, No.6, November 2012

\section{REFERENCES}

[1] Rössler, O.E. (1979) “An equation for hyperchaos,” Physics Letters A, Vol. 71, pp 155-157.

[2] Matsumoto, T. \& Kobayashi, K. (1986) "Hyperchaos: laboratory experiment and numerical confirmation", IEEE Trans. on CAS, Vol. 33, pp 1143-1147.

[3] Chua, L.O., Kobayashi, K., Tamasevicius, A., Cenys, A., Mykolaitis, G., Namajunas, A. \& E. Lindberg, E. (1997) "Hyperchaotic oscillators with gyrators", IEE Electronic Letters, Vol. 33, pp 542544.

[4] Cuomo, K.M. \& Oppenheim, A.V. (1993) "Circuit implementation of synchronized chaos with applications to communications", Physical Review Letters, Vol. 71, pp 65-68.

[5] Kocarev, L. \& Parlitz, U. (1995) "General approach for chaotic synchronization with applications to communication”, Physical Review Letters, Vol. 74, pp 5028-5030.

[6] Tao, Y. (1999) "Chaotic secure communication systems - history and new results", Telecommun. Review, Vol. 9, pp 597-634.

[7] Smaoui, N., Karouma, A. \& Zribi, M. (2011) "Secure communications based on the synchronizaiton of the hyperchaotic Chen and the unified chaotic systems", Communications in Nonlinear Science and Numerical Simulation, Vol. 16, pp 3279-3293, 2011.

[8] Peng, J.H., Ding, E.J., Ding, M. \& Yang, W. (1996) "Synchronizing hyperchaos with a scalar transmitted signal," Physical Review Letters, Vol. 76, pp 904-907.

[9] Yassen, M.T. (2008) "Synchronization hyperchaos of hyperchaotic systems", Chaos, Solitons and Fractals, Vol. 37, pp 465-475.

[10] Zhu, C. (2012) "A novel image encryption scheme based on improved hyperchaotic sequences", Optics Communications, Vol. 285, pp 29-37.

[11] Pecora, L.M. \& Carroll, T.L. (1990) "Synchronization in chaotic systems", Phys. Rev. Lett., Vol. 64, pp 821-824.

[12] Ott, E., Grebogi, C. \& Yorke, J.A. (1990) "Controlling chaos”, Phys. Rev. Lett., Vol. 64, pp 11961199.

[13]Ho, M.C. \& Hung, Y.C. (2002) "Synchronization of two different chaotic systems by using generalized active control", Physics Letters A, Vol. 301, pp 424-428.

[14] Sundarapandian, V. (2011) "Global chaos synchronization of four-scroll and four-wing chaotic attractors by active nonlinear control," International Journal on Computer Science and Engineering, Vol. 3, No. 5, pp. 2145-2155.

[15] Sundarapandian, V. (2011) "Global chaos synchronization of Li and Liu-Chen-Liu chaotic systems by active nonlinear control," International Journal of Advances in Science and Technology, Vol. 3, No. 1, pp. 1-12.

[16]Liao, T.L. \& Tsai, S.H. (2000) "Adaptive synchronization of chaotic systems and its applications to secure communications", Chaos, Solitons and Fractals, Vol. 11, pp 1387-1396.

[17] Sundarapandian, V. (2011) "Adaptive control and synchronization of hyperchaotic Cai system", International Journal of Control Theory and Computer Modelling, Vol. 1, No. 1, pp 1-13.

[18] Sundarapandian, V. (2011) "Adaptive synchronization of hyperchaotic Lorenz and hyperchaotic Liu systems", International Journal of Instrumentation and Control Systems, Vol. 1, No. 1, pp 1-18.

[19] Sundarapandian, V. (2011) "Adaptive control and synchronization of Liu's four-wing chaotic system with cubic nonlinearity," International Journal of Computer Science, Engineering and Applications, Vol. 1, No. 4, pp 127-138.

[20] Sundarapandian, V. \& Karthikeyan, R. (2011) "Global chaos synchronization of Pan and Lü chaotic systems via adaptive control," International Journal of Information Technology, Convergence and Services, Vol. 1, No. 5, pp. 49-66.

[21] Yu, Y.G. \& Zhang, S.C. (2006) "Adaptive backstepping synchronization of uncertain chaotic systems", Chaos, Solitons and Fractals, Vol. 27, pp 1369-1375.

[22] Wu, X. \& Lü, J. (2003), "Parameter identification and backstepping control of uncertain Lü system," Chaos, Solitons and Fractals, Vol. 18, pp 721-729.

[23] Suresh, R, \& Sundarapandian, V. (2012) "Global chaos synchronization of WINDMI and Coullet chaotic systems by backstepping control”, Far East Journal of Mathematical Sciences, Vol. 67, No. 2, pp 265-287.

[24] Suresh, R. \& Sundarapandian, V. (2012) "Hybrid synchronization of n-scroll Chua and Lur'e chaotic systems via backstepping control with novel feedback”, Archives of Control Sciences, Vol. 22, No. 3, pp 255-278. 
[25] Yang, T. \& Chua, L.O. (1999) "Control of chaos using sampled-data feedback control”, Internat. J. Bifurcat. Chaos, Vol. 9, pp 215-219.

[26]Zhao, J. \& Lü, J. (2006) "Using sampled-data feedback control and linear feedback synchronization in a new hyperchaotic system," Chaos, Solitons \& Fractals, Vol. 35, pp. 376-382.

[27] Park, J.H. \& Kwon, O.M. (2003) "A novel criterion for delayed feedback control of time-delay chaotic systems", Chaos, Solitons and Fractals, Vol. 17, pp 709-716.

[28] Ma, H., Deshmukh, V., Butcher, E. \& Averina, V. (2005) "Delayed state feedback and chaos control for time-periodic systems via a symbolic approach", Communications in Nonlinear Science and Numerical Simulation, Vol. 10, No. 5, pp 479-497.

[29] Konishi, K., Hirai, M. \& Kokame, H. (1998) "Sliding mode control for a class of chaotic systems", Physics Letters A, Vol. 245, pp 511-517.

[30] Sundarapandian, V. (2011) "Global chaos synchronization of four-wing chaotic systems by sliding mode control", International Journal of Control Theory and Computer Modelling, Vol. 1, No. 1, pp 15-31.

[31] Sundarapandian, V. (2011) "Global chaos synchronization of Pehlivan systems by sliding mode control”, International Journal on Computer Science and Engineering, Vol. 3, No. 5, pp 2163-2169.

[32] Sundarapandian, V. (2011) "Sliding mode controller design for the synchronization of ShimizuMorioka chaotic systems", International Journal of Information Sciences and Techniques, Vol. 1, No. 1, pp 20-29.

[33]Li, Y., Tang, W.K.S. \& Chen, G. (2005) "Generating hyperchaos via state feedback control", International Journal of Bifurcation and Chaos, Vol. 15, No. 10, pp 3367-3375.

[34]Bao, B.C. \& Zhong, L. (2008) “A hyperchaotic attractor coined from chaotic Lü system”, Chinese Physics Letters, Vol. 25, No. 7, pp 2396-2399.

[35] Hahn, W. (1967) The Stability of Motion, Springer, New York.

\section{Author}

Dr. V. Sundarapandian earned his Doctor of Science degree in Electrical and Systems Engineering from Washington University, St. Louis, USA in May 1996. He is Professor and Dean of the R \& D Centre at Vel Tech Dr. RR \& Dr. SR Technical University, Chennai, Tamil Nadu, India. He has published over 290 publications in refereed international journals. He has published over 180 papers in National and International Conferences. He is an India Chair of AIRCC. He is the Editor-in-Chief of the AIRCC Control Journals - IJICS, IJCTCM, IJITCA, IJCCMS and IJITMC. His research interests are Linear and Nonlinear

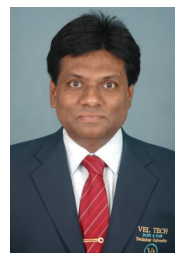
Control Systems, Chaos Theory and Control, Soft Computing, Optimal Control, Operations Research, Mathematical Modelling and Scientific Computing. He has served as Conference Chair of many International Conferences. He has delivered many Keynote Talks and Special Lectures on Linear and Nonlinear Control Systems, Chaos Theory, Fuzzy Logic, Mathematical Modelling, Scientific Computing, MATLAB and SCILAB. 